\title{
GLEEBLE MACHINE DETERMINATION OF CREEP LAW PARAMETERS FOR THERMALLY INDUCED DEFORMATIONS IN ALUMINIUM DC CASTING
}

\author{
Ivar Farup \\ SINTEF Materials Technology \\ Oslo, Norway \\ Jean-Marie Drezet \\ Laboratoire de Métallurgie Physique \\ Ecole Polytechnique Fédérale de Lausanne, $M X-G$ \\ Lausanne, Switzerland \\ Asbjørn Mo \\ SINTEF Materials Technology \\ Oslo, Norway \\ Terje Iveland \\ Hydro Aluminum R\&D Centre \\ Sunndalsøra, Norway
}

\begin{abstract}
By means of a Gleeble machine, the flow stress at steady-state creep in an AA3103 aluminium alloy has been measured for temperatures and strain rates relevant for thermally induced deformations in DC casting. The strain rate has been determined by measuring the global radial strain rate at the specimen center by an extensometer, and the stress has been set equal to the force in the axial direction divided by the cross-section area. The parameters of Garofalo's equation have been fitted to the resulting steady-state stress and strain rate. Such a method is based upon the assumption of homogeneous stress and strain rate fields. In the Gleeble machine, the specimens are heated by the Joule effect leading to axial temperature gradients, and the specimen geometry is noncylindrical. The resulting inhomogeneities in the stress and strain rate fields are studied by finite element modeling, and it is shown that although they can be significant, the global radial strain rate and the axial force divided by the cross-section area at the specimen center can be relatively close to what the respective strain rate and stress values would have been if the conditions actually were homogeneous.
\end{abstract}

In order to understand, optimize, and design the aluminium direct chill (DC) casting process, mathematical modeling is being used intensively, addressing the

Received 21 September 1998; accepted 24 December 1998.

Dr. Michel Bellet, CEMEF, is greatly acknowledged for valuable suggestions. The authors would also like to thank Ola Gikling, Hydro Aluminium, for assistance during the experiments. This rese arch has been funded by Hydro Aluminium, Elkem Aluminium, Hydro Raufoss Automotive Research Center, and the Research Council of Norway through the project PROSMAT-Støperikompetanse.

Address correspondence to Mr. Ivar Farup, Research Scientist, SINTEF Materials Technology, P.O. Box 124 Blindern, N-0314 Oslo, Norway. 
heat and fluid flow, the microstructure development, and the thermally induced deformation and associated stress generation in the solidifying ingot. Important input to the latter class of models is a constitutive law relating the viscoplastic strain rate to the flow stress, temperature, and strain.

Different constitutive models for viscoplastic deformation of the metal have been used to compute the stress generation during semicontinuous casting, notably of aluminium alloys. Moriceau [1] and Janin [2] used a temperature-dependent elastoplastic model, where as Brody et al. [3] assumed steady-state creep behavior in their analysis. Fjar and Mo [4] developed the finite element model ALSPEN in which viscoplastic deformation is modeled by a modified Ludwig constitutive law [5]. The same material model was used in the model developed by Magnin et al. [6]. The internal state variable constitutive model developed by Sample and Lalli [7] was used by Smelser and Richmond [8] to compute the air gap formation. This constitutive model, as well as the MATMOD equations developed by Miller [9], was also implemented in the three-dimensional version of ALSPEN [10]. Based on the ABAQUS ${ }^{1}$ software, Drezet and Rappaz [11] recently developed a three-dimensional mathematical model in which the steady-state creep law according to Garofalo [12] was applied to describe the solid state, whereas the semisolid state was described by a Norton-Hoff law.

The parameters occurring in the constitutive laws are usually determined by tensile and /or compression testing. Nedreberg [5] performed tensile testing of an AA6063 alloy with a Schenck Trebel RM100 equipped with a furnace and used the results to fit the modified Ludwig equation. Wisniewski and Brody [13] performed tensile tests on partially solidified aluminium-copper alloys giving stress-strain curves for different solid fractions and grain sizes. Creep tests were used by Drezet and Rappaz [11] to determine the parameters of Garofalo's equation, where as the coefficients of the Norton-Hoff law describing the semisolid state were determined by the indentation test designed by Vicente-Hernantez et al. [14].

With conventional equipment for tensile testing, temperature control is not straight forward. The Gleeble ${ }^{2}$ machine provides possibilities for dealing with these problems as well as handling the low strain rates $\left(10^{-6}-10^{-2} \mathrm{~s}^{-1}\right)$ characteristic of thermally induced deformations. Using the Gleeble machine, Magnin et al. [6] determined the parameters of a modified Ludwig viscoplastic law for an $\mathrm{HA} 14.5 \% \mathrm{Cu}$ alloy at temperatures between $50^{\circ} \mathrm{C}$ and $450^{\circ} \mathrm{C}$ and strain rates in the range of $10^{-3} \mathrm{~s}^{-1}$ to $10^{-2} \mathrm{~s}^{-1}$. By means of a one-dimensional numerical model, they computed the stress-time curve from the experimental strain-time curve and found the optimal rheological parameters using a downhill simplex optimization procedure [15] to minimize the error between computed and experimental stress curves. Except for their study, no work on the use of the Gleeble machine for the determination of flow stress relevant for thermally induced strains in DC casting of aluminium is known to the authors.

\footnotetext{
${ }^{1}$ ABAQUS is a general purpose finite element code from Hibbit, Karlsson \& Sorensen Inc., Pawtucket, RI, USA.

${ }^{2}$ Gleeble is a registered trademark of Dynamic Systems Inc.
} 
According to the results of Nedreberg [5], the steady-state creep regime is reached after approximately $2 \%$ straining at $400^{\circ} \mathrm{C}$ and almost immediately at $500^{\circ} \mathrm{C}$ and above in the AA6063 alloy. Results from ALSPEN [16] and other models reviewed previously indicate that viscoplastic straining at temperatures above $400^{\circ} \mathrm{C}$ gives a significant contribution to the total deformations occurring during the casting process. Knowledge of steady-state creep properties for industrial alloys is thus important in modeling casting processes.

Steady-state creep tests applied to an AA3103 alloy are reported in the present article. Testing has been carried out at temperatures between $325^{\circ} \mathrm{C}$ and $550^{\circ} \mathrm{C}$ and strain rates between $10^{-6} \mathrm{~s}^{-1}$ and $10^{-2} \mathrm{~s}^{-1}$, and the parameters of Garofalo's steady-state creep law are fitted to the experimental results. The inhomogeneities in the stress and strain rate fields caused by the thermal gradient [17] and noncylindrical Gleeble specimen geometry are then discussed. For this purpose, a two-dimensional axisymmetric numerical model of the Gleeble test was developed using the ABAQUS software. This model is also used to discuss the thermally induced deformations in the specimen during heating.

\section{GLEEBLE TESTS}

A schematic representation of the Gleeble test equipment is shown in Figure 1. The specimen is heated by the Joule effect, and water cooled jaws assure a high heat extraction at each side. Thus, only a small section at the center is held at the prescribed temperature, and the stress and strain rate vary in the axial direction of the specimen due to the temperature dependency of the flow stress. During the test, the temperature at the jaws increases slightly. The associated thermal expansion is experimentally indistinguishable from the elongation caused by viscoplastic deformation if the elongation of the specimen is to be used to determine the viscoplastic strain. Due to these phenomena, the diameter, measured at the specimen center by an extensometer, is applied to determining the stress and strain rate. In order to ensure that the position of maximum straining really is at the

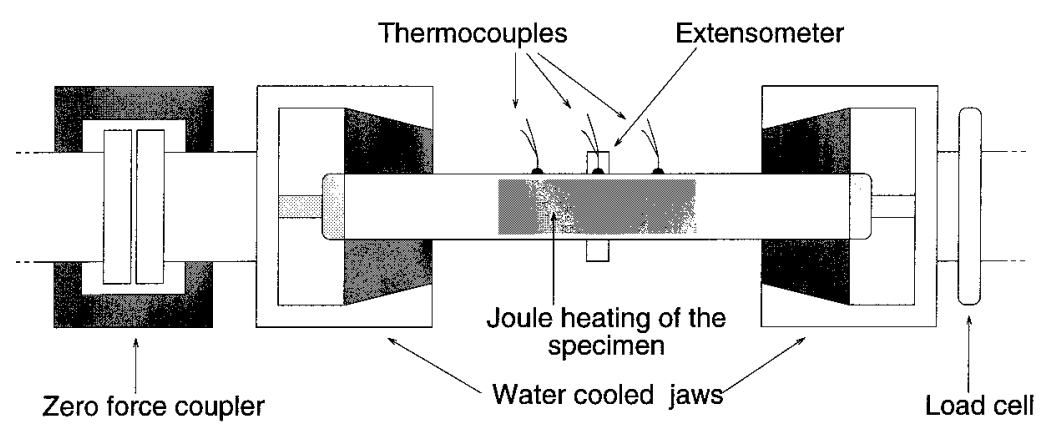

Figure 1. Schematic representation of the Gleeble machine. 
$90 \mathrm{~mm}$ (initial value)

Measurement of diameter, D, by an extensometer

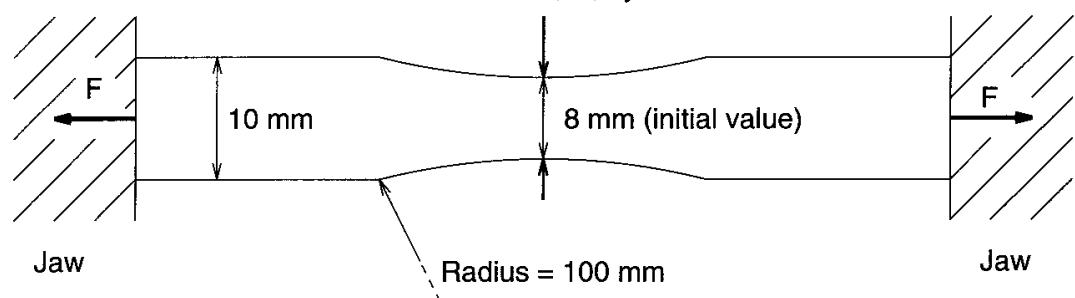

Figure 2. Gleeble specimen with circular cross section. Only the free part of the specimen is shown, and $F$ is the axial force at the jaws.

specimen center at which the controlling thermocouple is fixed, a slightly curved specimen geometry as indicated in Figure 2 is used.

The length of the specimen (initially $90 \mathrm{~mm}$ between the jaws) was chosen to obtain the low strain rates characteristic of thermally induced deformations in DC casting. At the lower strain rates (i.e., $10^{-6}-10^{-5} \mathrm{~s}^{-1}$ ) the rate of elongation of the specimen caused by thermal expansion is of the same order of magnitude as the elongation rate needed for the viscoplastic deformation, and it decreases during the experiment. Thus, to obtain a constant strain rate, the experiments were carried out with a constant, prescribed force instead of a constant jaw velocity. For each of the four testing temperatures, $325^{\circ} \mathrm{C}, 400^{\circ} \mathrm{C}, 475^{\circ} \mathrm{C}$, and $550^{\circ} \mathrm{C}$ at the specimen center, the different values of the chosen force resulted in a steady-state creep strain rate in the range of $10^{-6} \mathrm{~s}^{-1}$ to $10^{-2} \mathrm{~s}^{-1}$. A complete list of corresponding center temperature, $T$, and prescribed axial force, $F$, for the tests is given in Table 1 . The resulting steady-state creep strain rate, $\dot{\varepsilon}_{\mathrm{ss}}$, is also included in this table. Preliminary experiments were carried out at $250^{\circ} \mathrm{C}$. At this temperature, however, steady-state conditions were reached after approximately $10 \%$ straining. Since the accumulated viscoplastic strain caused by thermally induced deformations in DC casting is about $2 \%$, steady-state creep is not a relevant deformation mechanism at this temperature. As a consequence, experimental results obtained at $250{ }^{\circ} \mathrm{C}$ were not used to fit the parameters of Garofalo's equation.

In order to reduce the problems associated with precipitation hardening, the specimens were heated to the testing temperatures at a rate of $20 \mathrm{Ks}^{-1}$. During the heating period the specimens were free to move in the axial direction. Since the concentrations of $\mathrm{Mg}$ and $\mathrm{Si}$ are very low in AA3103 (Table 2), the only precipitation reaction that could possibly occur would be that of $\mathrm{Al}_{6} \mathrm{Mn}$ or $\alpha$-AlMnSi. Diffusion of $\mathrm{Mn}$ is, however, slow compared to the duration of the experiments, and the hardening effect of the resulting particles is small. The effect of precipitation hardening during the experiments is thus believed to be negligible. 
Table 1 Prescribed center temperature, $T$, and axial force, $F$, and resulting steady-state creep strain rate, $\dot{\varepsilon}_{\mathrm{ss}}$, for the Gleeble tests

\begin{tabular}{lrcccc}
\hline$T$ & $F$ & $\dot{\varepsilon}_{\mathrm{ss}}$ & $T$ & $F$ & $\begin{array}{c}\dot{\varepsilon}_{\mathrm{ss}} \\
{\left[{ }^{\circ} \mathrm{C}\right]}\end{array}$ \\
\hline$[\mathrm{N}]$ & {$\left[\mathrm{s}^{-1}\right]$} & {$\left[{ }^{-1}\right]$} \\
\hline 325 & 1500 & $2.4 \times 10^{-5}$ & 400 & 700 & $1.6 \times 10^{-6}$ \\
325 & 1600 & $7.0 \times 10^{-5}$ & 400 & 800 & $1.6 \times 10^{-5}$ \\
325 & 1800 & $4.5 \times 10^{-4}$ & 400 & 900 & $7.4 \times 10^{-5}$ \\
325 & 1800 & $4.3 \times 10^{-4}$ & 400 & 1000 & $2.7 \times 10^{-4}$ \\
325 & 2000 & $2.1 \times 10^{-3}$ & 400 & 1100 & $6.1 \times 10^{-4}$ \\
325 & 2000 & $9.6 \times 10^{-4}$ & 400 & 1200 & $1.9 \times 10^{-3}$ \\
325 & 2200 & $1.1 \times 10^{-3}$ & 400 & 1200 & $1.5 \times 10^{-3}$ \\
325 & 2200 & $1.4 \times 10^{-3}$ & & & \\
475 & 400 & $2.4 \times 10^{-6}$ & 550 & 200 & $1.0 \times 10^{-5}$ \\
475 & 500 & $1.5 \times 10^{-5}$ & 550 & 250 & $1.0 \times 10^{-5}$ \\
475 & 600 & $1.6 \times 10^{-4}$ & 550 & 300 & $2.4 \times 10^{-5}$ \\
475 & 650 & $4.3 \times 10^{-4}$ & 550 & 400 & $1.0 \times 10^{-4}$ \\
475 & 650 & $2.4 \times 10^{-4}$ & 550 & 450 & $6.3 \times 10^{-4}$ \\
475 & 700 & $2.5 \times 10^{-4}$ & 550 & 480 & $2.7 \times 10^{-4}$ \\
475 & 800 & $3.1 \times 10^{-4}$ & 550 & 550 & $1.1 \times 10^{-3}$ \\
475 & 800 & $2.1 \times 10^{-3}$ & 550 & 600 & $6.4 \times 10^{-3}$ \\
475 & 850 & $3.0 \times 10^{-3}$ & & & \\
475 & 900 & $5.6 \times 10^{-2}$ & & & \\
\hline
\end{tabular}

According to preliminary experiments, and in agreement with the results of Walsh et al. [17], the temperature profile in the axial direction was found to be parabolic. The temperature difference between the center and the jaws varies between the experiments due to different thermal contact between the specimen and the jaws. It begins in the range of $100 \mathrm{~K}$ to $170 \mathrm{~K}$, and decreases during the tests due to the heating of the jaws. The temperature variation over the cross section of the specimen was found to be negligible in preliminary experiments.

\section{EXPERIMENTAL RESULTS}

During the experiments, the force in the axial direction as well as the diameter at the center were measured as functions of time. The effective stress, $\sigma$, and the effective viscoplastic strain, $\varepsilon$, were determined as if the temperature were homo-

Table 2 Composition (wt\%) of the AA3103 alloy investigated in the present study

\begin{tabular}{cccc}
\hline $\mathrm{Fe}$ & $\mathrm{Si}$ & $\mathrm{Mg}$ & $\mathrm{Mn}$ \\
\hline 0.4928 & 0.0720 & 0.0035 & 1.0496 \\
\hline
\end{tabular}


ge neous and the specimen cylindric, that is,

$$
\begin{gathered}
\sigma=\frac{F}{A} \\
\varepsilon=-2\left[\ln \frac{D}{D_{0}}+\frac{v \sigma}{E}\right]
\end{gathered}
$$

where $D, D_{0}, F, A, E$, and $v$ denote current diameter, diameter at the start of testing, axial force, current cross-section area, Young's modulus, and Poisson's ratio, respectively. The values for the latter two material constants are taken from [18].

A typical output from a Gleeble test is shown in Figure 3 in which $\sigma$ and $\varepsilon$ given by Eqs. (1) and (2), respectively, are plotted versus time in a test with $F=500 \mathrm{~N}$ and temperature at the center equal to $475^{\circ} \mathrm{C}$. It is seen that the strain rate reaches steady state after a short transient period. The viscoplastic strain rate at steady state, $\dot{\varepsilon}_{\mathrm{ss}}$, is defined as the slope in the period during which the curve is approximately linear. During this period, $\sigma=F / A$ increases only slightly due to the small reduction in cross-section area and the steady-state stress, $\sigma_{\mathrm{ss}}$, is defined as its average value.

Each Gleeble test resulted in a set of values for $\dot{\varepsilon}_{\mathrm{ss}}, \sigma_{\mathrm{ss}}$, and $T$ that are all shown in Figure 4. The scattering observed in the figure results mainly from two sources of error. First, the initially circular cross section of the specimen was found to be slightly elliptic when measured on the cold specimens after the experiments.

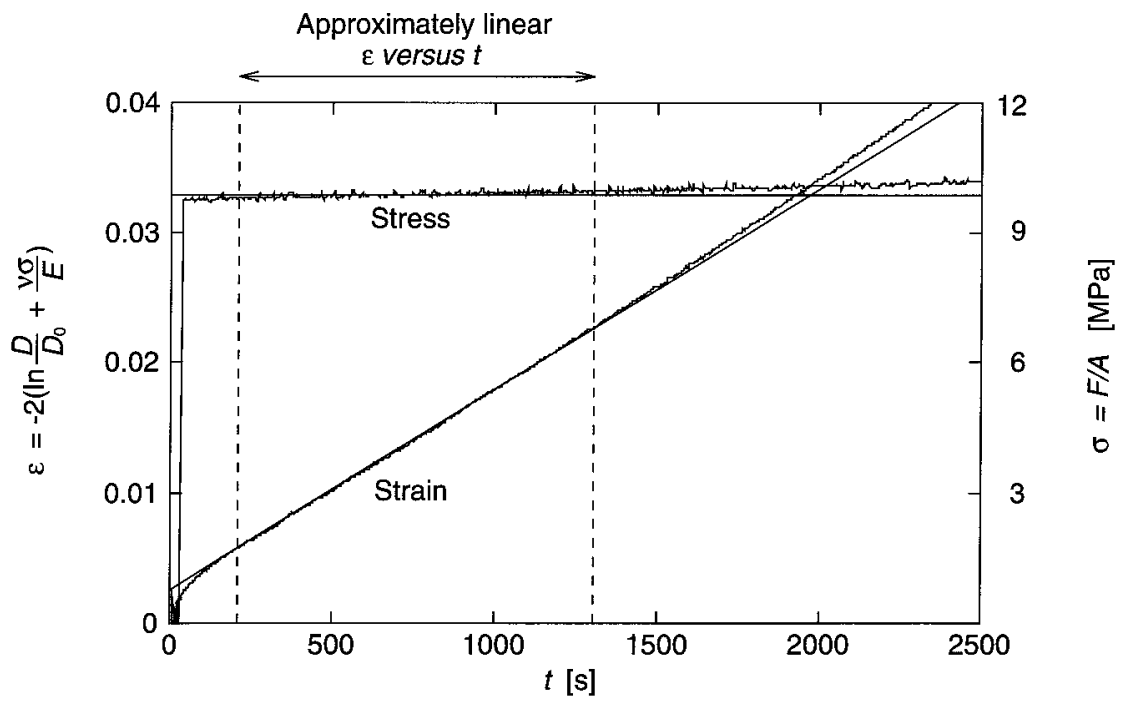

Figure 3. Gleeble test output for jaw force, $F$, equal to $500 \mathrm{~N}$, and temperature at the center equal to $475^{\circ} \mathrm{C}$. The straight lines indicate the steady-state stress and strain rate, respectively. 


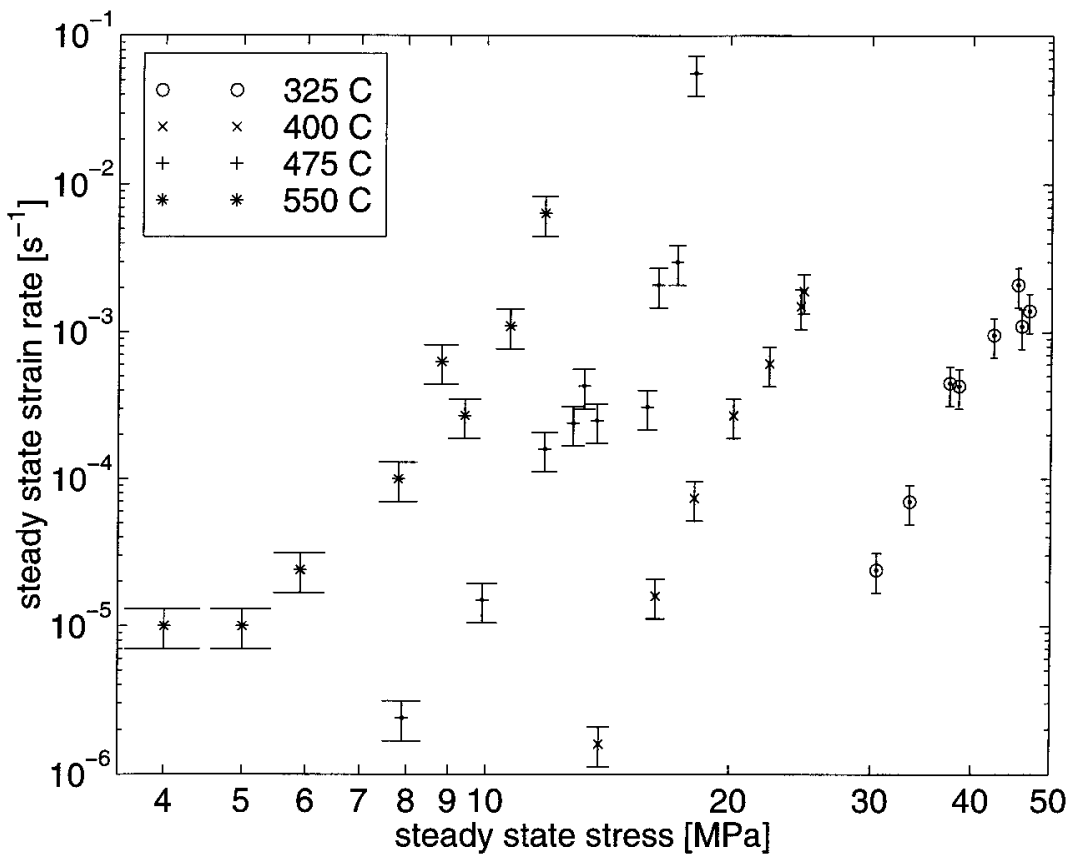

Figure 4. The steady-state viscoplastic strain rate, $\dot{\varepsilon}_{\mathrm{ss}}$, and steady-state stress, $\sigma_{\mathrm{ss}}$, obtained from Gleeble tests at the four temperatures $325^{\circ} \mathrm{C}, 400^{\circ} \mathrm{C}, 475^{\circ} \mathrm{C}$, and $550^{\circ} \mathrm{C}$. The error bars correspond to an uncertainty of $\pm 30 \%$ in the viscoplastic strain rate resulting mainly from anisotropic straining.

The difference in change of diameter from the initial state between the minor and major axes of the elliptic cross section was as high as 50 to $80 \%$. This anisotropy is the major source of inaccuracy in the determination of the steady-state strain rate, $\dot{\varepsilon}_{\text {ss }}$, and the error bars in Figure 4 correspond to an uncertainty of $\pm 30 \%$. For six of the tests, two parallel experiments were conducted (cf. Table 1). The resulting differences in viscoplastic strain rate were in the range of 20 to $50 \%$. Secondly, at low stress levels, the noise from the load cell measurement of the stress, which is approximately $\pm 0.2 \mathrm{MPa}$, be comes significant.

Garofalo's equation

$$
\dot{\varepsilon}_{\mathrm{ss}}=A \exp \left(-\frac{Q}{R T}\right)\left[\sinh \left(\frac{\sigma_{\mathrm{ss}}}{\sigma_{0}}\right)\right]^{n}
$$

has been fitted to the measurements at steady-state creep by minimizing the error function

$$
\operatorname{Err}\left(A, Q, \sigma_{0}, n\right)=\sum_{\text {all exp }}\left\{\ln \left(A \exp \left(-\frac{Q}{R T}\right)\left[\sinh \left(\frac{\sigma_{\mathrm{ss}}}{\sigma_{0}}\right)\right]^{n}\right) \ln \left(\dot{\varepsilon}_{\mathrm{ss}}\right)\right\}^{2}
$$


Table 3 Parameters in Garofalo's equation for steady-state creep of AA3103

\begin{tabular}{cccc}
\hline$A$ & $Q / R$ & $\sigma_{0}$ & $n$ \\
\hline $1.33 \times 10^{16} \mathrm{~s}^{-1}$ & $29012 \mathrm{~K}$ & $31.6 \mathrm{MPa}$ & 7.94 \\
\hline
\end{tabular}

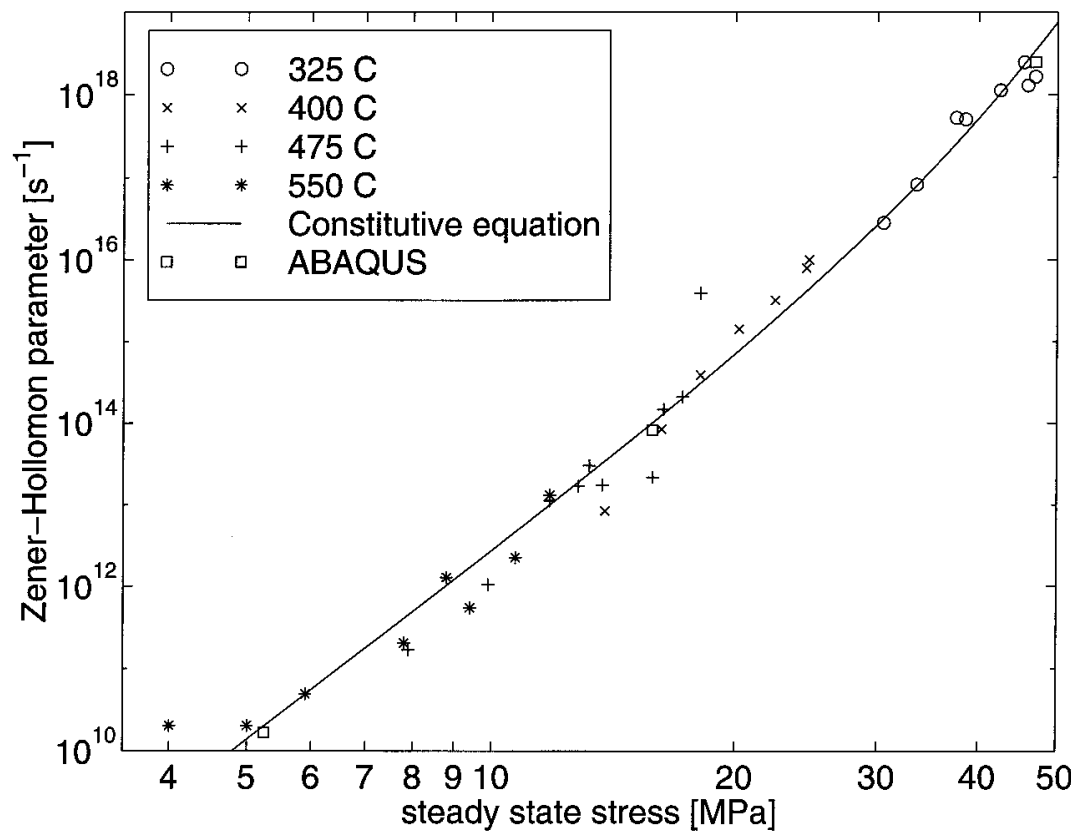

Figure 5. Gleeble test results for an AA3103 alloy during steady-state creep. The Zener-Hollomon parameter, $Z=\dot{\varepsilon}_{\mathrm{ss}} \exp (Q / R T)$ is plotted versus the steady-state stress, $\sigma_{\mathrm{ss}}$. The solid curve is the creep law given by Eq. (3), and the squares represent ABAQUS calculations of $\dot{\varepsilon}_{\mathrm{s} s}$ and $\sigma_{\mathrm{ss}}$ during steady-state creep.

by means of the downhill simplex optimization procedure [15]. The resulting material parameters are listed in Table 3, and in Figure 5 the creep law is plotted along with the experimental data. ${ }^{3}$

\section{FINITE ELEMENT MODEL}

In order to investigate the inaccuracy associated with the inhomogeneous stress and strain rate fields caused by the axial thermal gradient and by using a noncylindrical specimen geometry, a finite element model of the Gleeble test has

\footnotetext{
${ }^{3}$ A preliminary set of fitted parameters was used by Mo et al. [19].
} 
been developed based on the ABAQUS software. The specimen geometry in the model is similar to that in the Gleeble testing and shown in Figure 2. The free part of the specimen is considered as the solution domain (which is reduced to a quarter due to the axial symmetry). This is subjected to a predefined axial velocity by the jaws. $^{4}$ The material is considered elasticviscoplastic; and the relation between stress, viscoplastic strain rate, and temperature is given by Eq. (3). The coefficients for Hookes's law are taken from [18]. Quadrilateral, bilinear, axisymmetric elements are used, and because the specimen geometry is smooth and the temperature varies smoothly over the specimen, 310 nodes have been found to give sufficient accuracy.

The temperature profile in the axial direction is considered as a known input to the model. It is a good approximation to the most inhomogeneous experimental situation to assume a parabolic profile with maximum at the specimen center being $175 \mathrm{~K}$ higher than at the jaws.

\section{MODELING RESULTS}

The inhomogeneities in the strain rate field induced by the axial temperature profile and by the curved geometry are quantified in Figure 6. In Figure 6(a), it is seen that the effective viscoplastic strain rate varies between $1.84 \times 10^{-4} \mathrm{~s}^{-1}$ at the center and $1.61 \times 10^{-4} \mathrm{~s}^{-1}$ at the surface, that is, by $12.5 \%$. The effective stress, and thereby the effective viscoplastic strain rate, yields a maximum in the center of the specimen like during necking of ordinary tensile specimens [20]. Figure 6(b) quantifies the inhomogeneity in $\dot{\varepsilon}$ induced by the curved geometry alone (homogeneous temperature), while Figure $6(c)$ reveals the inhomogeneity induced by the axial temperature gradient when the specimen is a cylinder. It is seen that the temperature variation along the specimen axis and the curving both contribute to the inhomogeneity.

Three cases with different temperatures and strain rates were modeled. The jaw velocity and temperatures in the specimen center and at the surface in contact with the jaw are given in Table 4 for these three cases. Steady-state conditions similar to those in the experiments develop in the ABAQUS modeling (although the transient phase is different from the experimental situation due to the neglect of work hardening in the constitutive equations). In Figure 5 steady-state values of $\dot{\varepsilon}_{\mathrm{ss}}$ and $\sigma_{\mathrm{ss}}$ for the three cases are displayed as squares. The stress and strain rate histories were determined from the simulation results using Eqs. (1) and (2), and the corresponding steady-state values were obtained in exactly the same way as for the experimental cases. Similar to the situation after necking in tensile specimens, $\sigma=F / A$ is a slight overestimate of the effective stress [20]. It is however seen that the discrepancy between the simulation results and the solid curve representing the

\footnotetext{
${ }^{4}$ Although the experiments were carried out at a constant prescribed force, it has been found convenient to impose an axial velocity as a boundary condition in the modeling, as this simplifies the control of the resulting strain rate. Similar results and the same conclusion from the modeling can be drawn if a force is imposed as a boundary condition instead of a jaw velocity.
} 


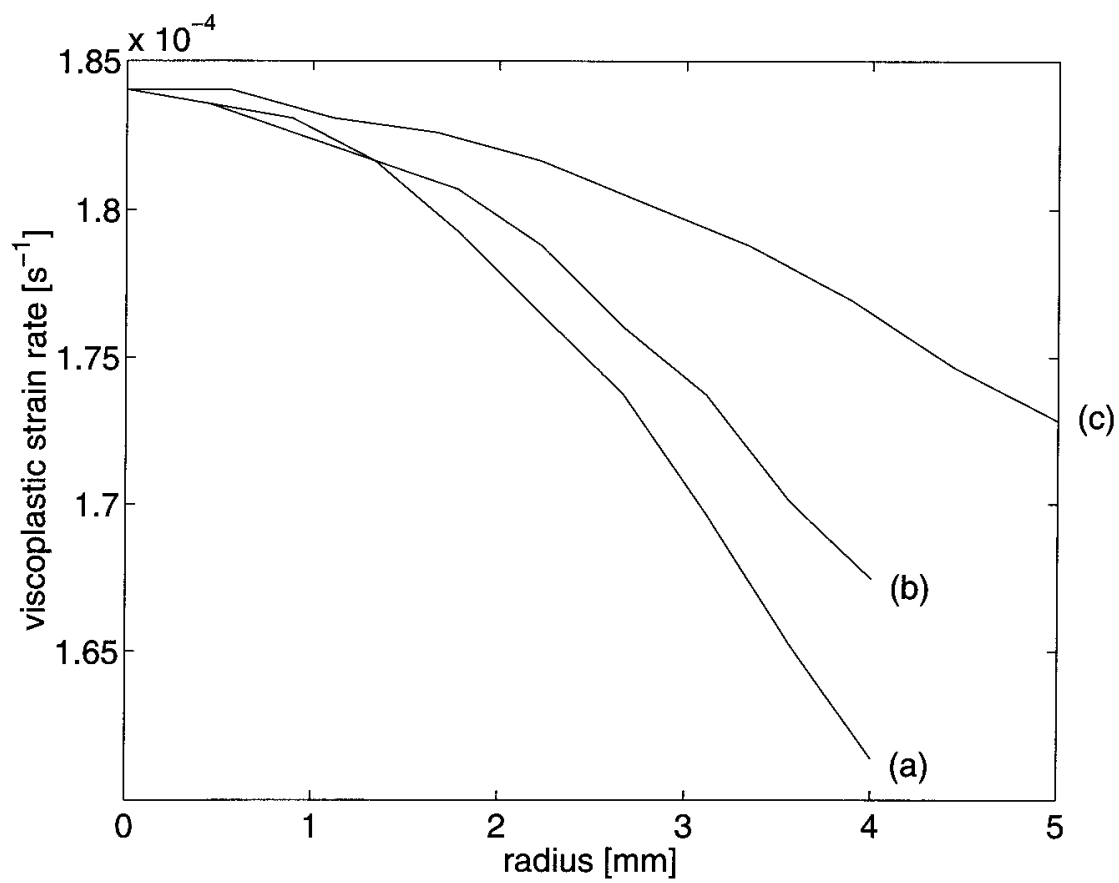

Figure 6. ABAQUS calculated effective viscoplastic strain rate, $\dot{\varepsilon}$, versus radial distance from the specimen center, $r$, during steady state in three cases, all with $440^{\circ} \mathrm{C}$ and a viscoplastic strain rate of $1.84 \times 10^{-4} \mathrm{~s}^{-1}$ at the specimen center. (a) Same specimen and temperature distribution as in the experiments, $(b)$ specimen with a homogeneous temperature (same geometry as in the experiments), $(c)$ cylindrical specimen (diameter $10 \mathrm{~mm}$ ) with the same temperature distribution as in the experiments.

constitutive law (being input to the ABAQUS modeling) is quite small and definitely smaller than the average distance between the solid curve and the experimental points. The experimental uncertainty is, in other words, larger than the error associated with applying $\dot{\varepsilon}_{\mathrm{ss}}$ and $\sigma_{\mathrm{ss}}$ as measures for strain rate and stress, respectively.

The nonconstancy of the temperature gradient during heating before testing gives rise to thermal stresses and thereby induced viscoplastic strains. In order to investigate the magnitude of this effect, the heating of the specimen has been simulated with the ABAQUS model by applying a realistic temperature history to a

Table 4 ABAQUS case studies

\begin{tabular}{ccc}
\hline $\begin{array}{l}\text { Jaw velocity } \\
{\left[10^{-6} \mathrm{~ms}^{-1}\right]}\end{array}$ & $\begin{array}{c}\text { Temperature } \\
\text { center }\left[{ }^{\circ} \mathrm{C}\right]\end{array}$ & $\begin{array}{c}\text { Temperature } \\
\text { jaw surface }\left[{ }^{\circ} \mathrm{C}\right]\end{array}$ \\
\hline 0.05 & 550 & 375 \\
1 & 440 & 265 \\
10 & 325 & 150 \\
\hline
\end{tabular}


specimen that was free to move. The temperature distribution over the specimen started out as homogeneous $20^{\circ} \mathrm{C}$ and increased linearly to a parabolic distribution with $375^{\circ} \mathrm{C}$ at the jaws and $550^{\circ} \mathrm{C}$ at the center during a period of $27 \mathrm{sec}$. The thermal expansion coefficient was set constant and equal to $30 \times 10^{-6}$. The resulting viscoplastic strain in the center of the specimen before the specimen was subjected to any external force was of the order of $10^{-9}$. In other words, it is not necessary to account for the thermally induced strains associated with the inhomoge neous heating when material parameters valid for the DC casting process are to be extracted by means of a Gleeble machine.

\section{CONCLUSION}

- A Gleeble test for determining steady-state creep law parameters has been defined and applied to an as-cast AA3103 alloy. The experiments were carried out at temperatures between $325^{\circ} \mathrm{C}$ and $550^{\circ} \mathrm{C}$ and strain rates in the range of $10^{-6}$ to $10^{-2} \mathrm{~s}^{-1}$, that is, at temperatures and strain rates relevant for thermally induced deformations in DC casting.

- The parameters of Garofalo's equation for steady-state creep were fitted to the results by means of the downhill simplex optimization technique.

- Inhomogeneities in the stress and strain rate fields caused by the thermal gradient and noncylindric specimen geometry have been studied by finite element modeling showing that the relative differences in effective viscoplastic strain rate along the radius at the specimen center is about $12.5 \%$.

- It is showed that the error associated with applying the global radial strain rate and the axial force divided by the cross-section area at the specimen center as measures of strain rate and stress, respectively, is negligible compared to other sources of experimental inaccuracy.

\section{REFERENCES}

1. J. Moriceau, Thermal Stresses in DC Casting of Al Alloys, in R. Rentsch (ed.), Light Metals, Vol. 2, pp. 119-133, TMS-AIME, Warrendale, PA, 1975.

2. B. Janin, Simulation of Thermal Stresses in Continuous Casting of Al Alloys Billets, in E-MRS meeting, pp. 305, Strasbourg, 1986.

3. H. D. Brody, P. Wisniewskih, A. G. Gokhale, and J. Mathew, Tensile Behaviour of Solid Plus Liquid Alloys in Relation to Thermal Stress Analysis of Solidification Processes, in A. F. Giamei and G. J. Abbaschian (eds.), Modeling and Control of Casting and Welding Processes IV, pp. 351-360, TMS, Warrendale, PA, 1988.

4. H. G. Fjær and A. Mo, ALSPEN-A Mathematical Model for Thermal Stresses in D.C. Casting of Aluminium Billets, Metallurgical Trans., vol. 21B, pp. 1049-1061, 1990.

5. M. L. Nedreberg, Thermal Stress and Hot Tearing during the DC Casting of AlMgSi Billets, Ph.D. Thesis, University of Oslo, Feb. 1991.

6. B. Magnin, L. Katgerman, and B. Hannart, Physical and Numerical Modelling of Thermal Stress Generation during DC Casting of Aluminium Alloys, in M. Cross and J. Campbell (eds.), Modelling of Casting, Welding and Advauced Solidification Processes-VII, pp. 303-310, TMS-AIME, Warrendale, PA, 1995. 
7. V. M. Sample and L. A. Lalli, Effects of Thermomechanical History on Hardness of Aluminium, Materials Sci. Tech., vol. 3, pp. 28-35, 1987.

8. R. E. Smelser and O. Richmond, Constitutive Model Effects on Stresses and Deformations in a Solidifying Circular Cylinder, in A. F. Giamei and G. J. Abbaschian (eds.), Modeling and Control of Casting and Welding Processes IV, pp. 313-328, TMS, Warrendale, PA, 1988.

9. A. K. Miller, Unified Constitutive Equations, chap. 3, pp. 139-219, Elsevier Applied Science, Amsterdam, 1987.

10. H. G. Fjær and A. Hakonsen, The Mechanism of Pull-in during DC-casting of Aluminium Sheet Ingots, in TMS-Annual Meeting, TMS-AIME, Orlando, Florida, 1997.

11. J.-M. Drezet and M. Rappaz, Modelling of Ingot Distorsions during Direct Chill Casting of Aluminium Alloys, Metallurgical and Materials Trans., vol. 27A, pp. 3214-3225, Oct. 1996.

12. F. Garofalo, An Empirical Relation Defining the Stress Dependence of Minimum Creep Rate in Me tals, Trans. TMS-AIME, vol. 227, pp. 351, 1963.

13. P. Wisniewski and H. D. Brody, Tensile Behaviour of Solidifying Aluminum Alloys, in M. Rappaz, M. R. Özgü, and K. W. Mahin (eds.), Modeling and Control of Casting and Welding Processes V, pp. 273-278, TMS-AIME, Warrendale, PA, 1991.

14. P. Vicente-Hernandez, F. Decultieux, P. Schmidt, I. L. Svensson, and C. Levaillant, Mushy State Behavior: Rheological Characterization and Influence on Air Gap Formation, ISIJ International, vol. 35, pp. 805-812, 1995.

15. J. A. Nelder and R. Mead, A Simplex Method for Function Minimization, Computer J., vol. 7, pp. 308-313, 1964.

16. H. G. Fjær and E. K. Jensen, Mathematical Modelling of Butt Curl Deformation of Sheet Ingots. Comparison with Experimental Results for Different Starting Block Shapes, in J. M. Evans (ed.), Light Metals, pp. 951-959, TMS-AIME, Warrendale, PA, 1995.

17. D. W. Walsh, M. J. Cieslak, and W. F. Savage, Temperature Measurements in Resistance-Heated Specimens: Longitudinal Gradients, Welding J., vol. 65, pp. 184s-192s, 1986.

18. L. F. Mondolfo, Aluminium Alloys: Structure and Properties, Butter Worths, Boston, MA, 1976.

19. A. Mo, I. Farup, and J.-M. Drezet, Inhomogeneities in the Stress and Strain Rate Fields during Gleeble Testing, in J. L. Chenot, J. F. Agassant, P. Montmitonnet, B. Vergnes, and N. Billon (eds.), First ESAFORM Conference on Material Forming, Sophia Antipolis, France, March 1998.

20. P. W. Bridgman, The Stress Distribution at the Neck of a Tension Specimen, Trans. Amer. Soc. Metals, vol. 32, pp. 553-574, 1944. 